\title{
Effect of Chronic Hypoxia on Carotid Vascular Responses to Adenosine in Rats
}

\author{
Nisreen Mansour Abo-Elmaaty \\ Physiology Department, Mansoura Faculty of Medicine, \\ Al Mansoura University, Egypt
}

\begin{abstract}
Aim of the work: the present study aims at testing whether chronic hypoxia alters the dilator vascular responses of rat carotid circulation to adenosine-evoked fall in arterial blood pressure (ABP). The arterial blood pressure was lowered to the lower limit of cerebral autoregulatory range giving the chance to further study whether the carotid autoregulatory response to adenosine-evoked fall in $A B P$ is compromised by chronic hypoxia or not. A third aim is to investigate whether the role of tonically synthesized nitric oxide (NO) in dilator responses evoked by adenosine in carotid vasculature is different in chronic hypoxic rats. Study Design: the study was done using 2 comparable age groups of adult male Wistar rats; the first were breathing normal 21\% $\mathrm{O}_{2}$ (normoxic; $N$ ), whereas the second were made chronically hypoxic (CH) by breathing 12\% $\mathrm{O}_{2}$ for 3 weeks, while they were growing from 7 to 10 weeks. In anaesthetized rats, the carotid blood flow (CBF) and carotid vascular conductance (CVC) were recorded during a 3 min infusion of adenosine adjusted at a dose aimed at lowering $A B P$ to $60 \mathrm{~mm} \mathrm{Hg}$, the lower limit of autoregulatory range before and after a bolus dose of the nitric oxide synthase inhibitor L-NAME $\left(10 \mathrm{mg} \cdot \mathrm{kg}^{-1}\right)$. Results: in chronic hypoxic rats, the adenosine-induced fall in $A B P$ was associated with a significant increase in CVC but with no significant increase in CBF in contrast to the significant increase in $C B F$ noticed in $N$ rats. Also, adenosine-evoked increase in baseline CVC was significantly larger in $\mathrm{N}$ than in $\mathrm{CH}$ rats. Inhibition of nitric oxide synthase produced comparable changes on baseline values in $\mathrm{CH}$ as in $\mathrm{N}$ rats. In $C H$ rats, L-NAME did not attenuate the increase in CVC evoked by adenosine as it did in $N$ rats. However, after L-NAME, CBF increased in $\mathrm{CH}$ rats. Conclusion: From these results, it could be suggested that exposing rats to chronic hypoxia for 3 weeks does not compromise the carotid autoregulatory response to the fall in arterial blood pressure. However, it seems that adenosine does not exert an active vasodilatation in carotid circulation of $\mathrm{CH}$ rats as it does in $\mathrm{N}$ rats. Further, it seems that the adenosine-evoked increase in CBF in $\mathrm{CH}$ rats is largely nitric oxide-independent.
\end{abstract}

Key words: chronic hypoxia, carotid vasculature, adenosine, nitric oxide

\section{INTRODUCTION}

Hypoxia can develop acutely in conditions that interfere with proper delivery of $\mathrm{O}_{2}$ to the systemic circulation such as acute respiratory failure, shock and acute myocardial infarction. More commonly, hypoxia develops on a chronic basis. Chronic hypoxia is a common feature of chronic respiratory diseases such as 
chronic obstructive pulmonary diseases and some cardiovascular diseases. It is also a feature of chronic mountain sickness which occurs after prolonged residence at high altitudes $^{[1]}$.

Adenosine is released by hypoxia and mediates hypoxic vasodilatation in muscle and in brain helping to ensure better delivery of oxygen. Its role as one of the mediators for the vascular responses to acute systemic hypoxia in muscle and cerebral circulation is well documented ${ }^{[2-7]}$. Several studies have been performed on rat mesenteric and muscle circulations investigating and comparing the responses evoked by adenosine in chronically hypoxic $(\mathrm{CH})$ rats that breathed $12 \% \mathrm{O}_{2}$ and in normoxic $(\mathrm{N})$ rats breathing air ${ }^{[2-4]}$. The dilator responses of mesenteric and muscle arterioles to locally applied adenosine has been found to be similar in $\mathrm{N}$ and $\mathrm{CH}$ rats ${ }^{[4]}$. However, on exposure to an acute hypoxic stimulus, the arterioles of $\mathrm{CH}$ rats showed greater dilator response when compared to those of $\mathrm{N}$ rats suggesting an enhanced sensitivity to adenosine released by acute hypoxia in $\mathrm{CH}$ rats ${ }^{[4]}$.

On the other hand, studies on rat cerebral circulation have concluded that adenosine mediates the dilator response of cerebral vasculature to acute hypoxia $^{[5]}$. Thus, the hypoxicinduced dilatation of pial arteries and the associated increase in cerebral blood flow were attenuated by theophylline ${ }^{[6]}$. Hypoxic dilatation of pial arteries was also attenuated by adenosine deaminase, an enzyme that inactivates adenosine by converting it to its inactive metabolite, inosine ${ }^{[7]}$.
Moreover, the increases in cortical blood flow and cortical vascular conductance induced by systemic hypoxia were attenuated by the nonselective specific adenosine receptor antagonist, 8-phenyltheophylline ${ }^{[8]}$. However, there have been no studies on the responses evoked in the cerebral circulation of $\mathrm{CH}$ rats by adenosine given either locally or systemically. Therefore, the main aim of the present study was to test the carotid vascular responses of $\mathrm{CH}$ rats to adenosine. Adenosine infusion rate was adjusted to lower arterial blood pressure $(\mathrm{ABP})$ to $60 \mathrm{~mm} \mathrm{Hg}$, the lower limit of autoregulatory range for cerebral circulation [9] giving the chance to further study whether or not the carotid autoregulatory response to adenosine-evoked fall in ABP would be compromised by prolonged exposure to hypoxia.

On the other hand, the role of tonically released nitric oxide in the regulation of cerebral circulation in the rat has been documented by several studies that have shown that systemic administration of nitric oxide synthase (NOS) inhibitors causes a reduction in the cerebral vascular conductance and in cerebral blood flow ${ }^{[10-12]}$. Further, NO has been implicated in the regulation of cerebral blood flow during ischemia [13-15]. However, there is still controversy whether or not NO mediates the cerebral vasodilator responses to hypoxia. Some studies indicated that NO does not contribute to the increase in cerebral blood flow seen in systemic hypoxia in rat ${ }^{[10,16]}$, whereas other studies have shown that the dilator response evoked in rabbit cerebral arteries by hypoxia was 
attenuated by methylene blue, an inhibitor of the action of $\mathrm{NO}^{[17]}$, or by NOS inhibitors in the cerebral circulation of piglets ${ }^{[18]}$, and human [19]. Thus, another important aim of the present experiments was to investigate the role of $\mathrm{NO}$ in the carotid vascular responses to adenosine in rats adapted to chronic hypoxia.

\section{METHODS}

Experiments were performed using 16 male Wistar rats maintained at the age of $\sim 7$ weeks with body weights of $\sim 170$ grams in the animal unit (Medical Experimental Research Centre, Mansoura Faculty of Medicine, Al Mansoura University). All procedures were performed according to the guidelines of animal care in the field. The rats were kept for 3-4 weeks till the age of 10-11 weeks, the age of performing the acute experimental protocol. They were given standard rat chow and water ad libitum. The rats were divided into 2 groups; the first 8 rats were housed in usual cages and breathed room air as they served control normoxic $(\mathrm{N})$ rats. The second 8 rats were placed in 2 cages prepared to be supplied with $12 \% \mathrm{O}_{2}$ instead of the atmospheric air with $\mathrm{O}_{2}$ of $21 \%$ and that group served as chronically hypoxic $(\mathrm{CH})$ rats. The temperature was kept around $22-23{ }^{\circ} \mathrm{C}$, and the $\mathrm{CH}$ rats were fed similarly to the $\mathrm{N}$ rats. The rats breathed the hypoxic gas mixture throughout the 3-4 weeks except for $20 \mathrm{~min}$ daily, when the cages were cleaned.

On the day of experiment, the rats were weighed and transferred to the laboratory. The weight of $\mathrm{CH}$ rats was $319 \pm 10.6 \mathrm{gm}$, comparable to the $\mathrm{N}$ rats. During surgery, the $\mathrm{CH}$ rats breathed a hypoxic gas mixture of $12 \% \mathrm{O}_{2}$, the level of $\mathrm{O}_{2}$ to which they were acclimated. This was delivered across the main arm of a T-tube inserted into the trachea through a tracheotomy, while the other arm of the tube was sealed by a removable screw. Before the start of experimental protocol, arterial blood samples were taken via the femoral cannula for analysis of arterial blood $\mathrm{PaO}_{2}, \quad \mathrm{PaCO}_{2}$ and $\mathrm{pH}$ by using laboratory blood gas analyzer (Instrumentation Laboratory, MA, USA). In $\mathrm{CH}$ rats, the mean values of the arterial blood $\mathrm{PaO}_{2}, \mathrm{PaCO}_{2}$ and $\mathrm{pH}$ were; $51.5 \pm 2.4 \mathrm{~mm} \mathrm{Hg}, 26.95 \pm$ $1.01 \mathrm{~mm} \mathrm{Hg}$, and $7.4 \pm 0.02$ respectively, compared to $\mathrm{PaO}_{2}$ 80-90 $\mathrm{mm} \mathrm{Hg}, \mathrm{PCO}_{2} 36-40 \mathrm{~mm} \mathrm{Hg}$ and $\mathrm{pH}$ 7.39-7.42 in $\mathrm{N}$ rats. In all experiments, anesthesia was induced with cotton soaked with ether delivered into a box containing the rat. The rat was then transferred to an operating table and anaesthetized by sodium thiopental $(40 \mathrm{mg} / \mathrm{kg}$ IP). The right femoral artery and vein were exposed and cannulated with polythene tubing filled with heparinized saline $\left(25 \mathrm{U} \quad \mathrm{ml}^{-1}\right.$ physiological saline). Femoral artery cannula was used to directly measure the arterial blood pressure by connecting it to a pressure transducer, whereas the femoral vein cannula used for infusion of adenosine. Another cannula in left femoral vein was used for administration of the NO synthase (NOS) inhibitor L-nitro methyl arginine (L-NAME). A midline incision in the neck was done 
to locate and to allow exposure of the left common carotid artery that was carefully freed from the surrounding tissues, with care to avoid damaging the accompanying nerve trunks. Carotid blood flow (CBF) was recorded by means of a transonic flow probe connected to a flow meter. The end of the flow probe was filled with acoustic coupling gel to facilitate good ultrasonic conduction. Arterial pressure and CBF were sampled by a PowerLab/8S at $100 \mathrm{~Hz}$ and connected to a computer via a bridge amplifier (AD Instruments Pty Ltd., Australia). Mean arterial pressure (ABP) and heart rate (HR) were derived from the pressure signal and carotid vascular conductance (CVC) was computed as $\mathrm{CBF} / \mathrm{ABP}$ by PowerLab Chart software (AD Instruments Pty Ltd., Australia).

Protocol:

An equilibration period of at least 30 min was allowed following surgery so that all baselines stabilized. Then, the cardiovascular variables were recorded in response to a $3 \mathrm{~min}$ of adenosine infusion adjusted to induce a decrease in ABP to $\sim 60 \mathrm{~mm} \mathrm{Hg}$. In $\mathrm{N}$ rats the infusion rate needed was $2.5 \pm 0.07 \mathrm{mg} \mathrm{kg}^{-1} \mathrm{~min}^{-1}$, whereas in $\mathrm{CH}$ rats it was $1.1 \pm 0.2 \mathrm{mg} \mathrm{kg}^{-1}$. After the cardiovascular variables had stabilized again, a bolus dose of $\mathrm{N}_{-}{ }^{\mathrm{G}}$ nitro-L-arginine methyl ester (LNAME; $10 \mathrm{mgKg}^{-1} . \mathrm{iv}$; ${ }^{[20]}$ was given. This dose has been shown to increase baseline ABP, reduce femoral vascular conductance and attenuate dilator responses induced by infusion of adenosine ${ }^{[20]}$. After a period of $15 \mathrm{~min}$, the protocol was repeated as described above.

\section{Chemicals:}

All chemicals were obtained from (Sigma-Egypt). Adenosine and LNAME were dissolved in physiological saline $(0.9 \%)$; they were freshly prepared on the day of the experiment.

\section{Statistical Analysis:}

All results are expressed as mean \pm SEM. In each group, the baseline value of each variable before adenosine infusion was compared with the mean value over the $3 \mathrm{~min}$ of the adenosine infusion by Students' paired $t$-test before and after LNAME. Students' paired $t$-test was also used to compare baseline values before and $15 \mathrm{~min}$ after L-NAME. Comparison between $\mathrm{N}$ rats and $\mathrm{CH}$ rats was done using Factorial ANOVA with Scheffe's post-hoc test. $\mathrm{P}<0.05$ was considered significant.

\section{RESULTS}

Effect of chronic hypoxia on baselines: Table 1 shows the resting values of recorded cardiovascular variables in $\mathrm{N}$ rats and $\mathrm{CH}$ rats. The resting $\mathrm{ABP}$ and $\mathrm{HR}$ values of $\mathrm{CH}$ rats breathing $12 \% \mathrm{O}_{2}$ were comparable to those of $\mathrm{N}$ rats breathing air. The resting baseline values of $\mathrm{CBF}$ and $\mathrm{CVC}$ tended to be smaller in $\mathrm{CH}$ rats than in $\mathrm{N}$ rats, but when compared statistically, this difference was not significant $(p=0.1)$.

Responses evoked by adenosine before L-NAME: Original traces of responses evoked by adenosine in carotid vasculature of $\mathrm{N}$ rat and $\mathrm{CH}$ rat are shown in figures $1 \& 2$.

As mentioned in methods, the adenosine infusion rate was adjusted for the weight of each animal so that it 
lowered $\mathrm{ABP}$ to $\sim 60 \mathrm{~mm} \mathrm{Hg}$. Although the weights of $\mathrm{CH}$ rats (319 $\pm 10.6 \mathrm{~g})$ were comparable to $\mathrm{N}$ rats $(321 \pm 4.5 \mathrm{~g})$, the $\mathrm{CH}$ rats needed a lower dose of adenosine to achieve this outcome: $1.1 \pm 0.2 \mathrm{mg} \mathrm{kg}^{-1}$ in comparison to the higher dose in $\mathrm{N}$ rats of $2.5 \pm 0.07 \mathrm{mg} \mathrm{kg}^{-1}(\mathrm{p}<0.0001$ for $\mathrm{CH}$ vs. $\mathrm{N}$ rats). The mean results showed that in $\mathrm{CH}$ rats, the adenosineinduced fall in ABP was associated with an increase in CVC, but no significant change in $\mathrm{CBF}(\mathrm{p}=0.1$, Fig. 3). This was in contrast to the significant increase in $\mathrm{CBF}$ in response to a comparable fall in $\mathrm{ABP}$ in $\mathrm{N}$ rats. The absolute increase in CVC evoked by adenosine was significantly greater in $\mathrm{N}$ rats than in $\mathrm{CH}$ rats $(\mathrm{p}<0.05$, Fig. 3$)$. The absolute increase in $\mathrm{CBF}$ in response to adenosine-induced hypotension tended to be greater in $\mathrm{N}$ rats than in $\mathrm{CH}$ rats $(\mathrm{p}=0.05)$. In $\mathrm{CH}$ rats, adenosine induced a significant fall in $\mathrm{HR}$ whereas in $\mathrm{N}$ rats the fall in HR induced by adenosine was not significant.

Effect of L-NAME (10 mg $\left.\mathrm{kg}^{-1}\right)$ on baselines: In $\mathrm{CH}$ rats, L-NAME administration caused a significant increase in ABP that was associated with significant reduction in CVC and CBF comparable to the effects seen in $\mathrm{N}$ rats. L-NAME also induced a significant reduction in $\mathrm{HR}$ in $\mathrm{CH}$ rats as in $\mathrm{N}$ rats. Comparison between $\mathrm{N}$ rats and $\mathrm{CH}$ rats for the effect of $\mathrm{L}$ NAME did not reveal any significant difference between the two groups when the changes induced were compared as \% change from baseline (Fig.4)

Effect of L-NAME (10 mg $\left.\mathrm{kg}^{-1}\right)$ on adenosine-evoked responses: After LNAME, the baselines attained new levels as indicated above. L-NAME did not have measurable effect on the fall in ABP or HR induced by adenosine in $\mathrm{N}$ rats (Fig. 5) as well as in $\mathrm{CH}$ rats (Fig. 6).

In $\mathrm{N}$ rats, after L-NAME administration, the increase in CVC induced by adenosine was smaller than before L-NAME, but adenosine still evoked a significant increase in CBF (Fig. 5). By contrast, in $\mathrm{CH}$ rats, L-NAME did not affect the increase in CVC evoked by adenosine-induced hypotension. However, after LNAME, the increase in CVC was accompanied by a significant increase in CBF (Fig. 6)

Comparing the effect of LNAME (10 mg kg-1) on adenosineevoked responses in $\mathrm{N}$ rats and $\mathrm{CH}$ rats did not reveal any significant difference between the two groups in that the adenosine-evoked responses after L-NAME became comparable in $\mathrm{N}$ and $\mathrm{CH}$ rats: both showed increase in $\mathrm{CVC}$ and in $\mathrm{CBF}$. 
Table 1: Baseline values of cardiovascular variables recorded in normoxic $(\mathrm{N})$ rats breathing air ( $\mathrm{n}=8$, weight: $321 \pm 4.5 \mathrm{gm})$ and in chronic hypoxic $(\mathrm{CH})$ rats breathing $12 \% \mathrm{O}_{2}(\mathrm{n}=8$, weight: $319 \pm 10.6 \mathrm{gm})$

\begin{tabular}{|c|c|c|}
\hline & $N$ rats & CH rats \\
\hline $\mathrm{ABP}(\mathrm{mm} \mathrm{Hg})$ & $119.66 \pm 6.08$ & $120.80 \pm 3.17$ \\
\hline HR (b.p.m) & $390.46 \pm 17.63$ & $369.84 \pm 2.15$ \\
\hline CBF (ml min min $^{-1}$ & $2.32 \pm 0.44$ & $1.70 \pm 0.16$ \\
\hline $\mathrm{CVC}\left(\mathrm{ml} \mathrm{min} \mathrm{mm} \mathrm{Hg}^{-1}\right)$ & $0.019 \pm 0.003$ & $0.014 \pm 0.001$ \\
\hline
\end{tabular}

Values are mean \pm SEM. There was no significant difference between the two groups. Abbreviations: ABP; mean arterial pressure, HR; heart rate, CBF; carotid blood flow, CVC; carotid vascular conductance.

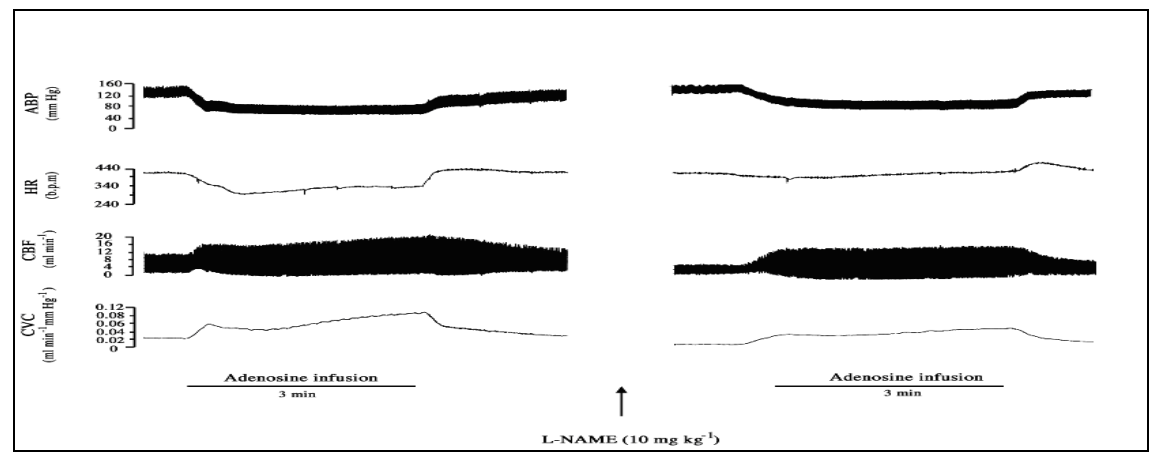

Fig 1. Original traces of cardiovascular responses evoked by a 3 min of adenosine infusion, aimed at lowering ABP to $\sim 60 \mathrm{~mm} \mathrm{Hg}$, before and after the NOS inhibitor L-NAME (10 $\mathrm{mg} \mathrm{kg}^{-1}$, i.v.), in normoxic rat.

Abbreviations: ABP; arterial blood pressure, HR; heart rate, CBF; carotid blood flow, CVC; carotid vascular conductance.

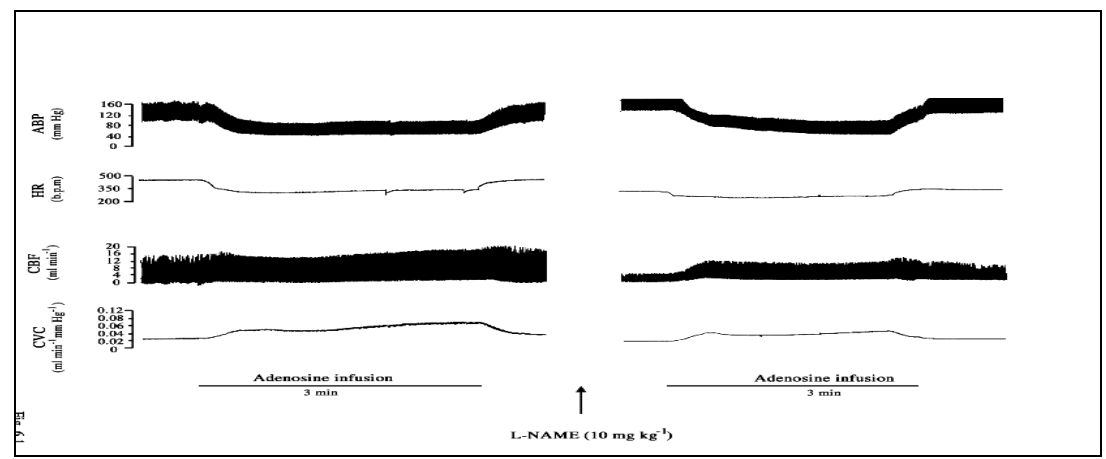

Fig.(2): Original traces of cardiovascular responses evoked by a 3 min of adenosine infusion, aimed at lowering ABP to $\sim 60 \mathrm{~mm} \mathrm{Hg}$, before and after the NOS inhibitor L-NAME (10 $\mathrm{mg} \mathrm{kg}^{-1}$, i.v.), in a chronically hypoxic rat.

Abbreviations: ABP; arterial blood pressure, HR; heart rate, CBF; carotid blood flow, CVC; carotid vascular conductance. 


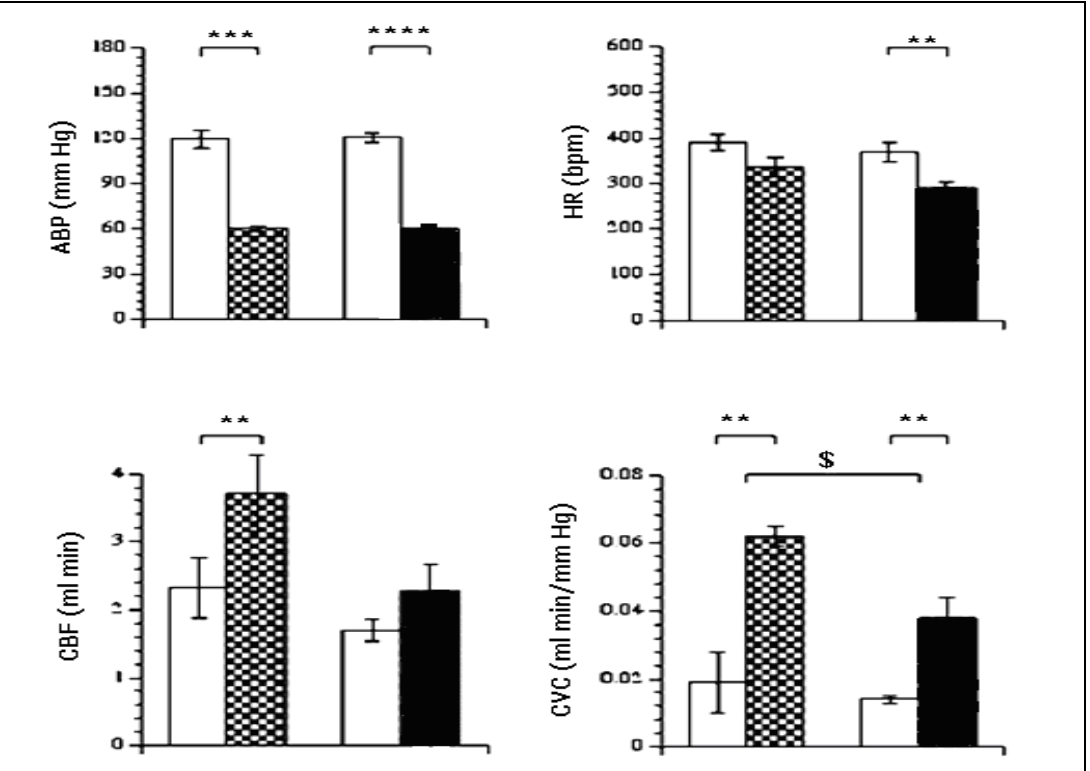

Fig.(3): Mean cardiovascular responses evoked by a 3 min of adenosine infusion (aimed at lowering of ABP to $\sim 60 \mathrm{~mm} \mathrm{Hg}$ ) in normoxic rats $(\mathrm{N})$ and in chronically hypoxic $(\mathrm{CH})$ rats $(\mathrm{n}=8 \& 8$ respectively). Values are mean \pm SEM.

$* *, * * *, * * * *: \mathrm{P}<0.01,0.001,0.0001$, indicating significant difference from values recorded before adenosine (Student's paired t-test). $\$: \mathrm{P}<0.05$, adenosine-evoked change in baseline CVC in N rats vs. CH rats (ANOVA, Scheffe's test).

Baseline value before adenosine infusion.

Adenosine-evoked responses in $\mathrm{N}$ rats.

Adenosine-evoked responses in $\mathrm{CH}$ rats.

Abbreviations: ABP; arterial blood pressure, HR; heart rate, CBF; carotid blood flow \& CVC; carotid vascular conductance.

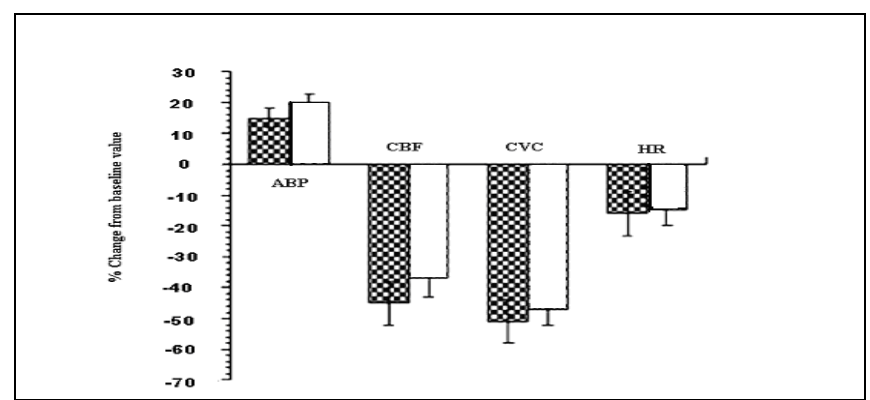

Fig. (4) Effect of L-NAME (10 mg kg-1 i.v.) on baseline value of cardiovascular variables presented as \% change from baseline in $\mathrm{N}$ rats $\quad \mathbf{0}$ and in $\mathrm{CH}$ rats $\square$. Values are mean \pm SEM. There was no significant difference between both groups (Factorial ANOVA). 


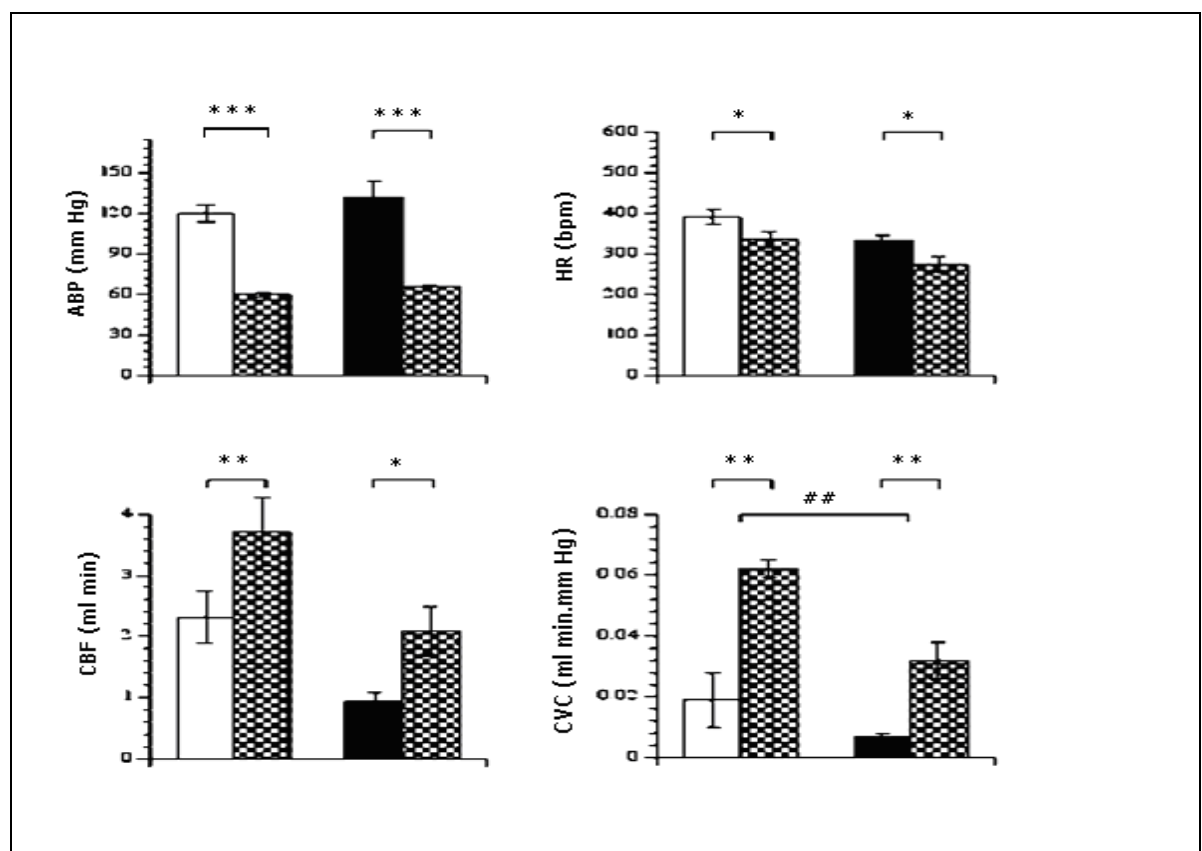

Fig. (5): Effect of L-NAME (10 $\left.\mathrm{mg} \mathrm{Kg}^{-1}\right)$ on adenosine-evoked responses in normoxic ( $\mathrm{N}$ rats, $\mathrm{n}=8$ ). Values are mean \pm SEM.

$*, * *, * * *: \mathrm{P}<0.05,0.01,0.001$ respectively indicating significant difference from baseline values recorded before adenosine infusion (Student's paired t-test).

\#\#: $\mathrm{P}<0.01$ indicating significant difference in the decrease in CVC after L-NAME.

Baseline value before $1^{\text {st }}$ adenosine infusion.

Adenosine-evoked response

Baseline value after L-NAME and before $2^{\text {nd }}$ adenosine infusion.

Abbreviations: ABP; arterial blood pressure, HR; heart rate, CBF; carotid blood flow \& CVC; carotid vascular conductance. 

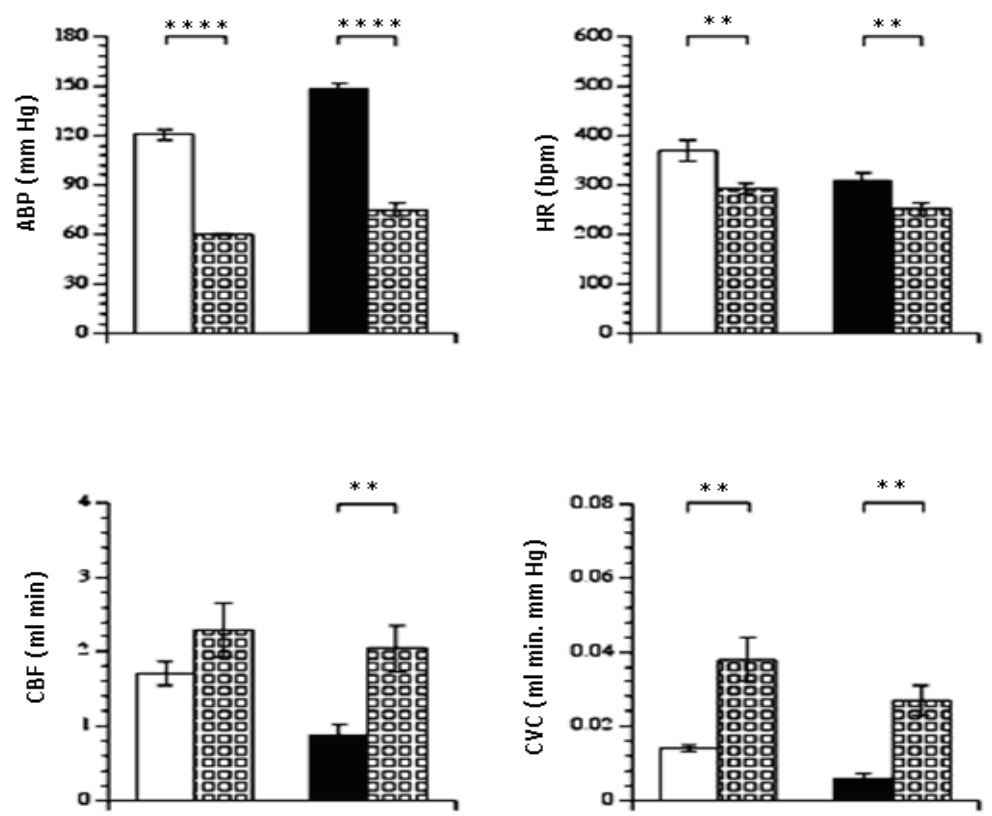

Fig. (6): Effect of L-NAME (10 $\mathrm{mg} \mathrm{kg}^{-1}$, i.v.) on adenosine-evoked responses in $\mathrm{CH}$ rats $(n=8)$. Values are mean \pm SEM.

$* *, * * * *: \mathrm{P}<0.01,0.0001$ respectively indicating significant difference from baseline values recorded before adenosine infusion (Student's paired t-test).
Baseline value before $1^{\text {st }}$ adenosine infusion $\&$ before L-NAME
Baseline value after L-NAME $\&$ before $2^{\text {nd }}$ adenosine infusion.
F. Adenosine-evoked responses.

Abbreviations: ABP; arterial blood pressure, HR; heart rate, $\mathrm{CBF}$; carotid blood flow \& CVC; carotid vascular conductance

\section{DISCUSSION}

The main aim of the present work was to study how the vascular responses of carotid vasculature of rats that were made chronically hypoxic by breathing $12 \% \mathrm{O}_{2}$ for 3-4 weeks would differ from the responses of the rats that mature for the same age while breathing normal $21 \% \quad \mathrm{O}_{2}$. The cerebral vascular responses to adenosine has been studied in conditions of acute hypoxia but none, to our knowledge, has studied it in chronically hypoxic rats.

On looking to the baseline values of cardiovascular variables of $\mathrm{CH}$ rats 
breathing $12 \% \mathrm{O}_{2}$, it is noticed that they were not significantly different from $\mathrm{N}$ rats breathing air, although $\mathrm{CVC}$ and $\mathrm{CBF}$ of $\mathrm{CH}$ rats tended to be smaller. This is consistent with the findings of a previous study in which $\mathrm{CBF}$ was measured as an index for cerebral blood flow ${ }^{[21]}$. In that study, there was no difference between baseline values of $\mathrm{CVC}, \mathrm{CBF}$ between $\mathrm{N}$ and $\mathrm{CH}$ rats. It may be noted that the adenosine receptor antagonist 8PT did not affect CVC in $\mathrm{CH}$ mature rats breathing $12 \% \mathrm{O}_{2}$, whereas it reduced $\mathrm{CVC}$ and $\mathrm{CBF}$ in $\mathrm{N}$ rats breathing air ${ }^{[21]}$. This suggests a tonic influence of adenosine is present in the carotid circulation of $\mathrm{N}$ rats, but not of $\mathrm{CH}$ rats. In $\mathrm{CH}$ rats, the adaptations that occur in response to chronic hypoxia ${ }^{[22,}$ 23] presumably mean that within 3-4 weeks $\mathrm{O}_{2}$ supply is well matched to the $\mathrm{O}_{2}$ demands of the brain such that adenosine is no longer released.

Regarding the carotid vascular responses to adenosine before LNAME, and as described in Methods, the $\mathrm{CH}$ rats needed a significantly lower concentration of adenosine than the $\mathrm{N}$ rats to evoke a comparable fall in $\mathrm{ABP}$ : i.e., $\mathrm{CH}$ rats were more sensitive to the hypotensive effect of adenosine. This might mean that the systemic circulation of $\mathrm{CH}$ rats is more sensitive to the dilator effect of adenosine than that of the $\mathrm{N}$ rats. However, the lower concentration of adenosine needed in $\mathrm{CH}$ rats may be explained on the basis that there is generalized increase in the structural vascular conductance in systemic circulation attributable to an increase in the number of arterioles and capillaries of skeletal muscle as a part of the remodelling and angiogenesis occurring during acclimation to chronic hypoxia ${ }^{[24]}$. Thus, a larger increase in muscle vascular conductance would be expected to lead to a greater fall in total peripheral resistance and therefore a greater fall in ABP. However, this increased sensitivity of the $\mathrm{CH}$ rats to the depressor effect of adenosine also raises a question as to whether chronic hypoxia may compromise the baroreflex control of ABP and this can be tested in future experiments. On the other hand, in the $\mathrm{N}$ rats, adenosine evoked an active vasodilatation, evidenced by the significant increase in $\mathrm{CBF}$, as the increase in CVC must have been larger than necessary to keep CBF constant. By contrast, in $\mathrm{CH}$ rats, $\mathrm{CBF}$ did not rise with the concomitant increase in CVC. Thus, it could be concluded that the autoregulatory response of $\mathrm{CH}$ rats to adenosineinduced hypotension was not compromised as they successfully faced the drop in ABP with an increase in CVC that was enough to prevent $\mathrm{CBF}$ from decreasing with the fall in ABP. On the other hand, the finding that $\mathrm{CBF}$ did not increase significantly in $\mathrm{CH}$ rats suggests that the carotid vasculature of $\mathrm{CH}$ rats did not show such active vasodilatation to adenosine as it did in $\mathrm{N}$ rats. Given that the carotid circulation of the $\mathrm{CH}$ rats was exposed to a lower concentration of adenosine than that of the $\mathrm{N}$ rats and because the cerebral circulation of the $\mathrm{CH}$ rats must have undergone angiogenesis and remodelling ${ }^{[23]}$ may give explanation for the decrease in vasodilatation evoked by adenosine in carotid 
vasculature of $\mathrm{CH}$ rats. However, the lack of significant increase in CBF in response to adenosine in $\mathrm{CH}$ rats in contrast to normoxic rats raises a possibility that the carotid vascular responses to endogenously released adenosine may be compromised by chronic hypoxia.

Regarding the effect of L-NAME on carotid vascular responses to adenosine, it is noted that L-NAME did not attenuate the fall in ABP or $\mathrm{HR}$ evoked by adenosine in $\mathrm{CH}$ rats as in $\mathrm{N}$ rats. However, in the $\mathrm{CH}$ rats, $\mathrm{L}-$ NAME at $10 \mathrm{mg} \mathrm{kg}^{-1}$ did not reduce the adenosine-evoked increase in $\mathrm{CVC}$, in contrast to $\mathrm{N}$ rats as $\mathrm{L}$ NAME significantly attenuated the increase in CVC evoked by Adenosine. This finding suggests that the active vasodilatation evoked by adenosine in carotid circulation in $\mathrm{N}$ rats was NO-dependent. On the other hand, the fact that adenosine evoked a significant increase in $\mathrm{CBF}$ in $\mathrm{CH}$ rats that did not occur before L-NAME indicates that the adenosine-induced increase in CVC that caused this increase in $\mathrm{CBF}$ is largely NOindependent.

Whether adenosine-evoked vasodilatation is mediated by $\mathrm{H}_{2} \mathrm{O}_{2}$ generated by superoxide dismutase as described by ${ }^{[25]}$ in mesenteric arteries or by an increase in endotheliumdependent hyperpolarizing factor is a question needing further investigations.

Another important aim of the present experiments was to test the role of basal nitric oxide in the carotid vasculature of $\mathrm{CH}$ rats. The present results indicated that the role of tonically synthesized NO in carotid vasculature was not different between the $\mathrm{N}$ rats that breathed air and $\mathrm{CH}$ rats that had adapted to breathing $12 \%$ $\mathrm{O}_{2}$. This conclusion can be drawn from the finding that L-NAME administration caused a comparable significant rise in $\mathrm{ABP}$ and a decrease in, $\mathrm{CVC}$ and $\mathrm{CBF}$ indicating generalized peripheral vasoconstriction, and, specifically, vasoconstriction in the carotid circulation (Fig. 4). Data from previous studies ${ }^{[26-29]}$ suggest that chronic hypoxia may alter the expression of eNOS differently in different vascular beds and this may explain why the role of $\mathrm{NO}$ was comparable in both groups of rats in the present experiments.

In conclusion, the present results indicate that, in rats exposed to chronic hypoxia, the autoregulatory response of carotid circulation to the fall in ABP evoked by adenosine was not compromised. Similarly, the role of basally released $\mathrm{NO}$ in regulation of basal carotid blood flow and conductance was comparable in $\mathrm{CH}$ and $\mathrm{N}$ rats. On the other hand, the results suggest also that adenosine did not evoke an active vasodilatation in carotid vasculature of $\mathrm{CH}$ rats in contrast to that noticed in $\mathrm{N}$ rats, and part of adenosine-induced vasodilatation is NO-dependent in $\mathrm{N}$ rats but it is largely NO-independent in $\mathrm{CH}$ rats. The fact that the $\mathrm{CH}$ rats showed high sensitivity to the depressor effect of adenosine (needed a much lower dose) raises a question whether the baroreflex control is compromised by prolonged exposure to hypoxia and this needs further investigation. 


\section{REFERENCES}

1. West JB. (2001): Pulmonary Physiology and Pathophysiology: An Integrated, Case-Based Approach. Philadelphia: Lippincott Williams \& Wilkins.

2. Marshall JM. (2001). Roles of adenosine and nitric oxide in skeletal muscle in acute and chronic hypoxia. Adv. Exp. Med. Biol., 502: 349-63.

3. Marshall JM. (2002). Roles of adenosine in skeletal muscle during systemic hypoxia. Clin. Exp. Pharmacol. Physiol., 29: 843-849.

4. Mian R, Marshall JM. (1996). The behavior of muscle microcirculation in chronically hypoxic rats: the role of adenosine. J. Physiol., 491: 489498.

5. Winn HR, Rubio R, Berne RM. (1981). Brain adenosine concentration during hypoxia in rats. Am. J. Physiol., 241: H235242.

6. Morii S, Ngai AC, Ko KR, Winn HR. (1987). Role of adenosine in regulation of cerebral blood flow: effects of theophylline during normoxia and hypoxia. Am. J. Physiol., 253 :H165-75

7. Simpson RE, Phillis JW. (1991). Adenosine deaminase reduces hypoxic and hypercapnic dilatation of rat pial arterioles: evidence for mediation by adenosine. Brain Res., 553(2):305-8.

8. Coney AM, Marshall JM. (1998). Role of adenosine and its receptors in the vasodilatation induced in the cerebral cortex of the rat by systemic hypoxia. $J$. Physiol., 509: 507-518.

9. Paulson OB. (2002). Bloodbrain barrier, brain metabolism and cerebral blood flow. European

Neuropsychopharmacol., $\quad \mathbf{1 2}$ : 495-501.

10. Buchanan JE, Phillis JW. (1993). The role of nitric oxide in the regulation of cerebral blood flow. Brain Res., 610: 248-255.

11. Prado R, Watson BD, Kuluz J, Dietrich WD. (1992). Endothelium-derived nitric oxide synthase inhibition. Effects on cerebral blood flow, pial artery diameter, and vascular morphology in rats. Stroke 23: 1118-1124.

12. Yang, S.T. (1996). Role of nitric oxide in the maintenance of resting cerebral blood flow during chronic hypertension. Life Sci., 58: 1231-1238.

13. Sato $S$, Tominaga $T$, Ohnishi $T$, Ohnishi ST. (1994). Electron paramagnetic resonance study on nitric oxide production during focal brain ischemia and reperfusion in the rat. Brain Res., 647: 91-96.

14. Tominaga T, Sato S, Ohnishi T, Ohnishi ST. (1993). Potentiation of nitric oxide formation following bilateral carotid artery occlusion and focal cerebral ischemia in the rat: in vivo detection of nitric oxide radical by electron paramagnetic resonance spin-trapping. Brain Res., 614: 342-346.

15. Zhang ZG, Chopp M, Zaloga C, Pollock JS, Forstermann U. 
(1993). Cerebral endothelial nitric oxide synthase expression after focal cerebral ischemia in rats. Stroke 24: 2016-2021.

16. Pelligrino DA, Koenig HM, Albrecht RF. (1993). Nitric oxide synthesis and regional cerebral blood flow responses to hypercapnia and hypoxia in the rats. J. Cereb. Blood Flow Metab., 13(1):80-7

17. Pearce WJ, Reynier-Rebuffel AM, Lee J, Aubineau P, Ignarro L, Seylaz J. (1990). Effects of methylene blue on hypoxic cerebral vasodilatation in the rabbit. J. Pharmacol. Exp. Ther., 254(2):616-25.

18. Armstead WM. (1995). Opioids and nitric oxide contribute to hypoxia-induced pial arterial vasodilatation in newborn pigs. Am. J. Physiol., 268: H226-H232.

19. Van Mil AH, Spilt A, Van Buchem MA, Bollen EL, Teppema L, Westendorp RG, Blauw GJ. (2002). Nitric oxide mediates hypoxia-induced cerebral vasodilatation in humans. J. Appl. Physiol., 92: 962-966.

20. Ray CJ, Marshall JM. (2005). Measurement of nitric oxide release evoked by systemic hypoxia and adenosine from rat skeletal muscle. J. Physiol., 568: 967-78.

21. Thomas T, Marshall JM. (1997). The roles of adenosine in regulating the respiratory and cardiovascular systems in chronically hypoxic, adult rats. $J$. Physiol.., 501: 439-447.

22. Mironov V, Hritz MA, LaManna JC, Hudetz AG,
Harik SI.(1994). Architectural alterations in rat cerebral microvessels after hypobaric hypoxia. Brain Res., 660: 73-80.

23. Xu K. \& LaManna JC. (2006). Chronic hypoxia in the cerebral circulation. J. Appl. Physiol., 100(2):725-30.

24. Deveci D, Marshall JM, Egginton S. (2002). Chronic hypoxia induces prolonged angiogenesis in skeletal muscles of rat. Exp. Physiol., 87: 287291.

25. Williams SJ, Hemmings DG, Mitchell JM, McMillen IC \& Davidge ST (2005b). Effects of maternal hypoxia or nutrient restriction during pregnancy on endothelial function in adult male rat offspring. J. Physiol., 565, 125-135.

26. Le Cras TD, Tyler RC, Horan MP, Morris KG, Tudor RM, McMurtry IF., Johns RA, Abman SH. (1998). Effects of chronic hypoxia and altered hemodynamics on endothelial nitric oxide synthase expression in the adult rat lung. J. Clin. Invest., 101: 795-801.

27. Shaul PW, North AG, Brannon TS, Ujiie K, Wells LB, Nisen PA, Lowenstein CJ, Snyder SH, Star RA. (1995). Prolonged in vivo hypoxia enhances nitric oxide synthase type I and type III gene expression in adult rat lung. Am. J. Resp. Cell \& Mol. Biol., 13: $167-174$.

28. Toporsian M, Govindaraju K, Nagi M, Eidelman D, Thibault G, Ward ME. (2000). Down regulation of endothelial nitric oxide synthase in rat aorta after 
prolonged hypoxia in vivo. Circ.

Res., 86: 671-5.

29. Walsh MP, Marshall JM.

(2006). The early effects of chronic hypoxia on the cardiovascular system in the rat: the role of nitric oxide. $J$. Physiol., 575: 263-75

\title{
تأثير النقص المزمن للاكسجين على دور الادينوسين فى الدورة الدمويه السباتية في الفئران دور الادينان
}

\author{
قسم الفسيولوجيا الطبية ـ كلية الطب أبوالمعاطى - جامعة المنصورة
}

اجرى هذا البحث لدراسة تأثير النقص المزمن للاكسجين على دور الادينوسين فى الدورة

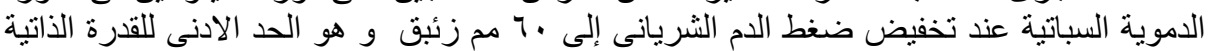

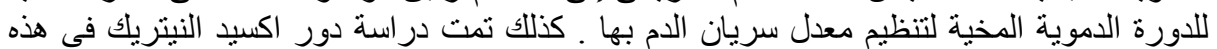

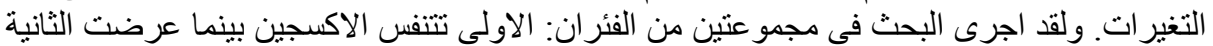

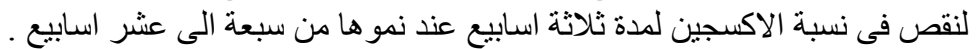

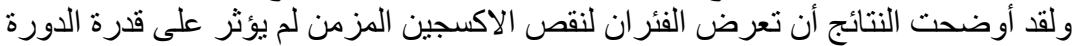

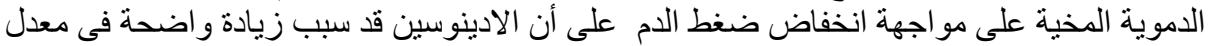

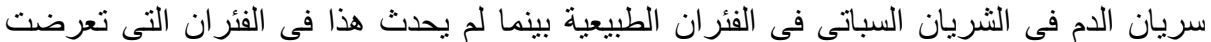

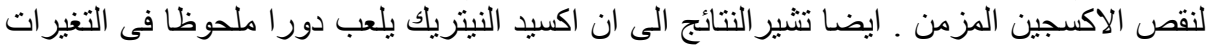

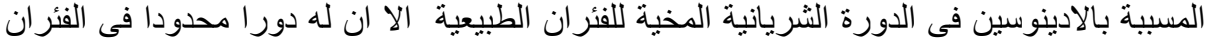

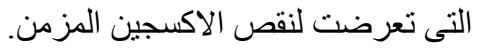

